\title{
Acute toxicity profile of craniospinal irradiation with intensity-modulated radiation therapy in children with medulloblastoma: A prospective analysis
}

Maurice C. Cox ${ }^{1}$, Johannes M. Kusters ${ }^{1}$, Corrie E. Gidding ${ }^{2}$, Jolanda H. Schieving ${ }^{3}$, Erik J. van Lindert ${ }^{4}$, Johannes H. Kaanders ${ }^{1}$ and Geert O. Janssens ${ }^{5^{*}}$

\begin{abstract}
Background: To report on the acute toxicity in children with medulloblastoma undergoing intensity-modulated radiation therapy (IMRT) with daily intrafractionally modulated junctions.

Methods: Newly diagnosed patients, aged 3-21, with standard-risk (SR) or high-risk (HR) medulloblastoma were eligible. A dose of 23.4 or 36.0Gy in daily fractions of 1.8Gy was prescribed to the craniospinal axis, followed by a boost to the primary tumor bed (54 or 55.8Gy) and metastases (39.6-55.8Gy), when indicated. Weekly, an intravenous bolus of vincristine was combined for patients with SR medulloblastoma and patients participating in the COG-ACNS0332 study. Common toxicity criteria (CTC, version 2.0) focusing on skin, alopecia, voice changes, conjunctivitis, anorexia, dysphagia, gastro-intestinal symptoms, headache, fatigue and hematological changes were scored weekly during radiotherapy.

Results: From 2010 to 2014, data from 15 consecutive patients (SR, $n=7 ; \mathrm{HR}, n=8)$ were collected. Within $72 \mathrm{~h}$ from onset of treatment, vomiting (66 \%) and headache (46\%) occurred. During week 3 of treatment, a peak incidence in constipation (33\%) and abdominal pain/cramping (40\%) was observed, but only in the subgroup of patients $(n=9)$ receiving vincristine (constipation: 56 vs $0 \%, P=.04$; pain/cramping: 67 vs $0 \%, P=.03$ ). At week $6,73 \%$ of the patients developed faint erythema of the cranial skin with dry desquamation (40\%) or moist desquamation confined to the skin folds of the auricle (33\%). No reaction of the skin overlying the spinal target volume was observed.
\end{abstract}

Conclusions: Headache at onset and gastro-intestinal toxicity, especially in patients receiving weekly vincristine, were the major complaints of patients with medulloblastoma undergoing craniospinal irradiation with IMRT.

Keywords: Craniospinal irradiation, Acute toxicity, IMRT, Medulloblastoma

\section{Background}

The technique of craniospinal irradiation (CSI) is indicated for medulloblastoma/PNET-tumors and some more rare tumors with leptomeningeal spread like germcell tumors, atypical teratoid rhabdoid tumors and ependymoma [1-6]. The most common malignant embryonal tumor of the central nervous system in childhood is

\footnotetext{
*Correspondence: g.o.r.janssens@umcutrecht.nl

${ }^{5}$ Department of Radiation Oncology, University Medical Center Utrecht and Princess Maxima Center for Pediatric Oncology, Utrecht 3584 CX, The Netherlands

Full list of author information is available at the end of the article
}

medulloblastoma $[7,8]$. The treatment of medulloblastoma usually includes a combination of surgical resection, radiotherapy and chemotherapy $[1,2]$. Currently, patients are categorized into standard-risk (SR) and highrisk (HR) groups. High-risk criteria include: positive cerebrospinal fluid cytology, or leptomeningeal metastasis on imaging, or residual tumor at primary site $>1.5 \mathrm{~cm}^{2}$, or extra-axial metastases [9]. More recently, patients with large-cell anaplastic medulloblastoma are added [10]. Today, the technique most commonly used for treating the craniospinal axis (CSA) is a combination of two lateral opposed cranial fields, matched to a posterior field to treat

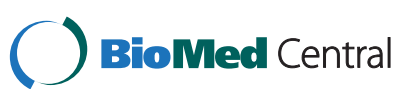

(c) 2015 Cox et al. Open Access This article is distributed under the terms of the Creative Commons Attribution 4.0 International License (http://creativecommons.org/licenses/by/4.0/), which permits unrestricted use, distribution, and reproduction in any medium, provided you give appropriate credit to the original author(s) and the source, provide a link to the Creative Commons license, and indicate if changes were made. The Creative Commons Public Domain Dedication waiver (http://creativecommons.org/publicdomain/zero/1.0/) applies to the data made available in this article, unless otherwise stated. 
the spine. This technique results in dose inhomogeneity, especially at the craniospinal junction and the spinalspinal junction if required, depending on the thecal length [11]. The conventional technique also leads to a significant dose to structures anterior to the vertebra (thyroid, heart, lungs, bone marrow, intestine, kidneys) and the skin overlying the spine $[11,12]$.

In order to reduce the dose to organs at risk without decreasing the target coverage, other techniques for CSI are developed. CSI with electrons for the spinal part can be used as an alternative for photons in small children [13]. Both electron and proton beam radiation provide substantial sparing of non-target tissues anterior to the vertebra compared with conventional photon CSI [13-15]. Intensity Modulated Radiation Therapy (IMRT) results in better target coverage, improved junction homogeneity and a large gain in healthy tissue sparing [16-18]. In patients undergoing CSI with helical tomotherapy, junctions-related uncertainties even do not exist, because only one set-up point is needed during the whole treatment [19]. Highly-conformal photon techniques might result in a reduction of acute and late toxicity. Most data published on acute toxicity during CSI are retrospective and focus on a limited number of items [13, 19-22]. Prospective cumulative toxicity data on nausea, vomiting, headache, skin reactions and infections are available for a subgroup of patients with medulloblastoma treated with conventional CSI in the HIT-91 trial [23].

The purpose of this prospective study is to report on the acute toxicity of patients with medulloblastoma during CSI by IMRT.

\section{Methods}

\section{Eligibility}

Newly diagnosed patients, with medulloblastoma, aged 3 to 21, were eligible for the prospective registration of acute toxicity during CSI using IMRT with daily intrafractionally modulated junctions [18]. Toxicity items focusing on skin reactions, alopecia, voice changes, conjunctivitis, anorexia, dysphagia, vomiting, diarrhea, constipation, abdominal cramping, headache, fatigue and hematological changes were scored from baseline until week 10 after onset of radiotherapy, by an experienced pediatric radiation oncologist. The Common Toxicity Criteria used for this study (CTC, version 2.0) are provided in Table 1. Patients with SR or HR medulloblastoma, who received induction chemotherapy after surgery and before the onset of radiotherapy or patients receiving anesthesia during treatment, were excluded from the current analysis. Approval for the study was obtained from the Radboud University Medical Centre research Ethics Committee. Informed consent was obtained before data collection.

\section{IMRT technique}

All patients underwent CSI with IMRT in supine position. Details of the procedure are described previously [18]. Briefly, treatment planning, using Pinnacle v.8.0 h software (Philips Medical Systems, Andover, MA), was based on a CT-scan obtained with a customized neck support (AccuForm Custom Cushions, Accuform, MEDTEC, Orange City, IA), a five-point fixation mask immobilization for the head (Efficast High- Precision Mask, Orfit Masks, Orfit Industries NV, Wijnegem, Belgium) and a cast for body fixation. The clinical target volume (CTV) was delineated comprising the entire brain and meninges for the cranial part. The spinal CTV contained the spinal canal as observed on CT-scan including the cerebrospinal fluid extension to the spinal ganglia. Based on MR-imaging, the inferior limit of the spinal CTV was defined at the caudal extent of the thecal sac. The spinal planning target volume (PTV) included an $8-\mathrm{mm}$ margin in the caudal direction and a $5 \mathrm{~mm}$ margin in the lateral, anterior and posterior directions. For the cranial part of the PTV two parallelopposed lateral photon fields were used, with segmental correction for overdose at the frontal and occipital area. Under- and overdosage of the craniospinal junction was prevented by including a daily intra-fractional beam displacement over a total length of 3 centimeters into the planning calculations. For this purpose, a 6-step junction was created by successively shifting the inferior borders of the two opposing cranial fields by $0.5 \mathrm{~cm}$. This induced dose inhomogeneity was subsequently compensated by IMRT optimization of the adjacent spinal fields. The spinal IMRT beam arrangement consisted of five coplanar photon beams with gantry angles at $250^{\circ}, 215^{\circ}$, $180^{\circ}, 145^{\circ}$, and $110^{\circ}$. Subsequent to CSI, patients received a boost with IMRT or VMAT (Volumetric Modulated Arc Therapy) to the primary tumor bed. On indication, additional boosts to spinal and or intracranial metastases were delivered with IMRT.

\section{Radiation therapy}

Radiotherapy was supposed to be initiated within 31 days following surgical resection. A dose of 23.4Gy or 36.0Gy in daily fractions of $1.8 \mathrm{~Gy}$ was prescribed to the CSA for patients with SR- or HR medulloblastoma, respectively. Subsequently, a boost dose of 30.6Gy (total dose SR: $54.0 \mathrm{~Gy}$ ) or $19.8 \mathrm{~Gy}$ (total dose HR: $55.8 \mathrm{~Gy}$ ) in daily fractions of $1.8 \mathrm{~Gy}$ was planned to the primary tumor site. Concomitantly patients with HR disease did receive an additional boost to doses ranging from 39.6-55.8Gy to the spinal and/or intracranial metastases.

\section{Chemotherapy}

Adjuvant chemotherapy, based on the regimen described by Packer et al., started 4 weeks after the end 
Table 1 National Cancer Institute Common Toxicity Criteria, version 2.0

\begin{tabular}{|c|c|c|c|c|c|}
\hline Adverse event & $\begin{array}{l}\text { Grade } \\
0\end{array}$ & Grade 1 & Grade 2 & Grade 3 & Grade 4 \\
\hline $\begin{array}{l}\text { Skin/radiation } \\
\text { dermatitis }\end{array}$ & None & $\begin{array}{l}\text { Faint erythema/dry } \\
\text { desquamation }\end{array}$ & $\begin{array}{l}\text { Moderate to brisk erythema } \\
\text { or patchy desquamation } \\
\text { mostly confined to skin folds }\end{array}$ & $\begin{array}{l}\text { Confluent moist desquamation } \\
\geq 1.5 \mathrm{~cm} \text { diameter, not confined } \\
\text { to skin folds, pitting edema }\end{array}$ & $\begin{array}{l}\text { Skin necrosis, ulceration } \\
\text { of full thickness, bleeding } \\
\text { not induced by trauma } \\
\text { or abrasion }\end{array}$ \\
\hline Alopecia & Normal & Mild hair loss & Pronounced hair loss & - & - \\
\hline Cough & Absent & $\begin{array}{l}\text { Mild, relieve by } \\
\text { non-prescription } \\
\text { medication }\end{array}$ & Requiring narcotic antitussive & $\begin{array}{l}\text { Severe cough or coughing } \\
\text { spasms, poorly controlled } \\
\text { or unresponsive to treatment }\end{array}$ & - \\
\hline $\begin{array}{l}\text { Voice changes } \\
\text { (hoarseness, } \\
\text { loss of voice) }\end{array}$ & Normal & $\begin{array}{l}\text { Mild or intermittent } \\
\text { hoarseness }\end{array}$ & $\begin{array}{l}\text { Persistent hoarseness but } \\
\text { able to vocalize, may have } \\
\text { mild to moderate edema }\end{array}$ & $\begin{array}{l}\text { Whispered speech, not able } \\
\text { to vocalize, may have marked } \\
\text { edema }\end{array}$ & $\begin{array}{l}\text { Marked dyspnea/stridor } \\
\text { requiring tracheostomy } \\
\text { or intubation }\end{array}$ \\
\hline Conjunctivitis & None & $\begin{array}{l}\text { Ophthalmologic changes } \\
\text { but asymptomatic (pain/ } \\
\text { irritation) or without visual } \\
\text { impairment }\end{array}$ & $\begin{array}{l}\text { Symptomatic/interfering } \\
\text { with function but not } \\
\text { interfering with activities } \\
\text { of daily living }\end{array}$ & $\begin{array}{l}\text { Symptomatic/interfering with } \\
\text { activities of daily living }\end{array}$ & - \\
\hline Anorexia & None & Loss of appetite & $\begin{array}{l}\text { Oral intake significantly } \\
\text { decreased }\end{array}$ & Requiring IV fluids & $\begin{array}{l}\text { Requiring feeding tube } \\
\text { or parenteral nutrition }\end{array}$ \\
\hline Dysphagia & None & Mild, can eat regular diet & $\begin{array}{l}\text { Requiring pureed, soft or } \\
\text { liquid diet }\end{array}$ & $\begin{array}{l}\text { Requiring feeding tube, IV } \\
\text { hydration/alimentation }\end{array}$ & $\begin{array}{l}\text { Complete obstruction, } \\
\text { cannot swallow saliva }\end{array}$ \\
\hline Vomiting & None & $1 \mathrm{x} / 24 \mathrm{~h}$ & $2-5 x / 24 h$ & $\geq 6 x / 24 \mathrm{~h}$ or need for IV fluids & $\begin{array}{l}\text { Requiring parenteral } \\
\text { nutrition, hemodynamic } \\
\text { collapse, I.C.U. }\end{array}$ \\
\hline Diarrhea & None & Increase $\leq 4 \mathrm{x} / 24 \mathrm{~h}$ & $\begin{array}{l}4-6 \times / 24 \text { h or nocturnal } \\
\text { stools }\end{array}$ & $\begin{array}{l}\geq 7 \times / 24 \text { h or incontinence, } \\
\text { or need for parenteral support } \\
\text { for dehydration }\end{array}$ & $\begin{array}{l}\text { Hemodynamic collapse, } \\
\text { I.C.U. }\end{array}$ \\
\hline Constipation & None & $\begin{array}{l}\text { Requiring stool softener } \\
\text { or dietary modification }\end{array}$ & Requiring laxatives & $\begin{array}{l}\text { Requiring manual evacuation } \\
\text { or enema }\end{array}$ & $\begin{array}{l}\text { Obstruction or } \\
\text { megacolon }\end{array}$ \\
\hline $\begin{array}{l}\text { Abdominal pain } \\
\text { or cramping }\end{array}$ & None & $\begin{array}{l}\text { Mild; not interfering with } \\
\text { function }\end{array}$ & $\begin{array}{l}\text { Moderate; pain or analgesics, } \\
\text { interfering with function but } \\
\text { not with activities of daily } \\
\text { living }\end{array}$ & $\begin{array}{l}\text { Severe; pain or analgesics } \\
\text { interfering with activities of } \\
\text { daily living }\end{array}$ & - \\
\hline Headache & None & $\begin{array}{l}\text { Mild; non interfering with } \\
\text { function }\end{array}$ & $\begin{array}{l}\text { Moderate; pain or analgesics, } \\
\text { interfering with function but } \\
\text { not with activities of daily living }\end{array}$ & $\begin{array}{l}\text { Severe; pain or analgesics } \\
\text { interfering with activities of } \\
\text { daily living }\end{array}$ & - \\
\hline Fatigue/malaise & None & $\begin{array}{l}\text { Increased fatigue, not } \\
\text { altering normal activities }\end{array}$ & $\begin{array}{l}\text { Moderate (decrease of } \\
\text { performance status - } 20 \% \text { in } \\
\text { Lansky or Karnofsky); difficulty } \\
\text { in performing some activities }\end{array}$ & $\begin{array}{l}\text { Severe (decrease of performance } \\
\text { status-40 \% in Lansky or } \\
\text { Karnofsky); loss of ability to } \\
\text { perform some activities }\end{array}$ & Disabling \\
\hline
\end{tabular}

of radiotherapy [24]. A weekly intravenous bolus of vincristine $\left(1.5-2.0 \mathrm{mg} / \mathrm{m}^{2}\right)$ was combined with radiotherapy for patients with SR medulloblastoma and HR medulloblastoma participating in the COG-ACNS0332 trial [10].

\section{Statistics}

Statistical analyses were performed with SPSS 21.0. Descriptive statistics were used to calculate median values (and $95 \%$ confidence intervals) of patient, tumor and treatment characteristics. The Chi-square test and Fisher's exact test were used to compare toxicity outcomes between different groups.

\section{Results and discussion}

\section{Patient and treatment characteristics}

Between March 2010 and December 2014, data from 19 consecutive patients with newly diagnosed medulloblastoma at the Radboud University Medical Centre, were collected. Four patients were excluded from analysis for reasons of induction chemotherapy $(n=3)$ and anesthesia $(n=1)$. The baseline patient and treatment characteristics are listed in Table 2.

The median age of the patient group was 8 years (range, 4-16 years). Radiation therapy started within 32 days from surgery in 14 of 15 children (median, 31 days; 95\%CI: 29-32 days; range, 15-42 days). All children completed radiotherapy within 43 days (median, 
Table 2 Patient and treatment characteristics

\begin{tabular}{|c|c|}
\hline Patient and treatment characteristics & \\
\hline \multicolumn{2}{|l|}{$\operatorname{Sex}(n)$} \\
\hline Male & 8 \\
\hline Female & 7 \\
\hline \multicolumn{2}{|l|}{ Age at diagnosis (years) } \\
\hline Median & 8 \\
\hline Range & $4-16$ \\
\hline \multicolumn{2}{|l|}{ Staging $(n)$} \\
\hline SR & 7 \\
\hline HR MO & 0 \\
\hline HR M1 & 4 \\
\hline HR M2 & 1 \\
\hline HR M3 & 3 \\
\hline \multicolumn{2}{|l|}{ Time between surgery and start RT (days) } \\
\hline Median & 31 \\
\hline Range & $15-43$ \\
\hline $95 \%$ Cl median & 29-32 \\
\hline \multicolumn{2}{|l|}{ CSI dose (n) } \\
\hline $23.4 \mathrm{~Gy} / 1.8$ & 7 \\
\hline $36.0 \mathrm{~Gy} / 1.8$ & 8 \\
\hline Patients receiving cranial/spinal boost ( $\mathrm{n}$ ) & 4 \\
\hline Cranial boost & 3 \\
\hline Spinal boost & 3 \\
\hline \multicolumn{2}{|l|}{ Overall treatment time RT (days) } \\
\hline Median & 42 \\
\hline Range & $39-43$ \\
\hline $95 \%$ Cl median & $41-42$ \\
\hline Patients with treatment interruptions ( $\mathrm{n}$ ) & 1 \\
\hline Treatment interruptions (days) & 1 \\
\hline \multicolumn{2}{|l|}{ Chemotherapy (n) } \\
\hline SR (Concomitant and Adjuvant) & 7 \\
\hline HR (Concomitant and Adjuvant) & 2 \\
\hline HR (Adjuvant only) & 6 \\
\hline
\end{tabular}

42 days; 95\%CI: 41-42 days; range, 39-43 days). Radiation therapy was interrupted for 1 day in one patient, due to lack of compliance. A weekly bolus of vincristine was given to all children with SR disease $(n=7)$. Two out of eight children with HR disease, participating in the COG-ACNS-0332 trial, received vincristine. Four patients with HR disease did receive additional boost doses to spinal and or intracranial metastases.

\section{Overall toxicity profile}

Within $72 \mathrm{~h}$ from start of treatment, headache and vomiting were observed in 46 and $66 \%$ of children, respectively (Fig. 1a and b). A peak incidence in constipation (33\%) was observed during week 3 (Fig. 1c). From the third week of radiotherapy, $40 \%$ of the children experienced mild (grade 1) or moderate (grade 2) abdominal pain/cramping (Fig. 1d). Anorexia was observed during the whole period of radiation treatment (Fig. 1e).

Pronounced hair loss occurred in all 15 patients from week 3 . At week $6,73 \%$ of the patients developed faint erythema of the occipital part of the cranial skin combined with dry desquamation (40\%), or moist desquamation confined to the skin folds of the auricle (33\%) (Fig. 1f). Radiation dermatitis of the skin overlying the spinal target volume was not observed. Conjunctivitis was not observed and dysphagia (grade 1), cough (grade 1) and voice changes (grade 1) were limited to 13,20 and $13 \%$ of all patients, respectively. Severe diarrhea (grade 3) was recorded in 1 patient, as a result of a Salmonella infection.

Before start of radiation therapy, $13 \%$ of the patients received treatment with corticosteroids. To relieve side effects of treatment, dexamethasone and ondansetron were prescribed. From week one to six (w1-6) low doses of dexamethason (range, $0.5-3.0 \mathrm{mg}$ per day) were used in $60,47,53,33,40$ and $40 \%$ of patients, respectively. Ondansetron was used by $47 \%$ (w1), $53 \%$ (w2), $53 \%$ (w3), $47 \%$ (w4), $40 \%$ (w5) and $33 \%$ (w6) of patients.

Without any use of hematopoiesis stimulating factors, the median value of white blood cells and platelet count at nadir was $2,2 \cdot 10^{9} / \mathrm{L}$ (range: $1,2-3,1$; normal: $4,0-10$ ) and $121 \cdot 10^{9} / \mathrm{L}$ (range: 41-177; normal: 150-400), respectively.

\section{Toxicity profile in relation to medulloblastoma risk groups}

The acute toxicity profile for headache, skin toxicity, anorexia, vomiting, constipation and abdominal cramping in patients with SR vs HR medulloblastoma is illustrated in Fig. 2. Although none of the toxicity items scored were significantly different between the SR and HR group, there was a trend $(P=0.13)$ towards an increased incidence of cranial/ear skin toxicity during the fifth week in the HR group.

\section{Toxicity profile in relation to intravenous vincristine use}

A comparison of acute gastro-intestinal toxicity (anorexia, abdominal pain/cramping, constipation and vomiting) in patients with $(n=9)$ and without $(n=6)$ concomitant intravenous vincristine is shown in Fig. 3. Anorexia was observed more frequently in patients receiving vincristine during weeks 3 to 6 . During week 3, constipation and abdominal pain/cramping occurred more frequently in the vincristine group (Fig. $3 \mathrm{c}$ and d). No significant difference in incidence of vomiting, skin reaction or headache was observed between the groups with and without vincristine. 


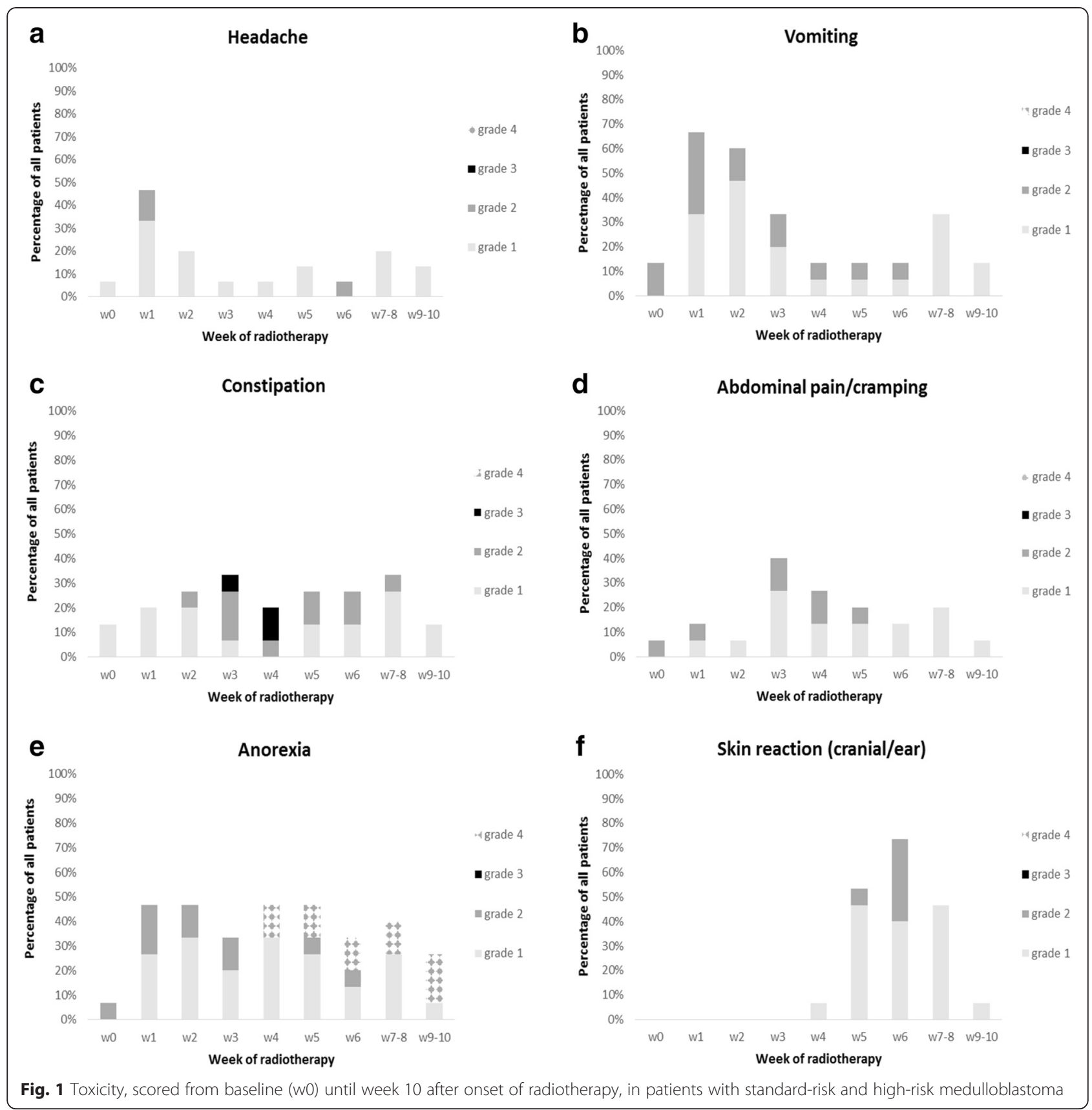

\section{Discussion}

Gastro-intestinal toxicity was the major complaint during radiotherapy in children with medulloblastoma undergoing CSI with IMRT. Subgroup analysis revealed the use of intravenous vincristine as main reason for gastro-intestinal toxicity. Headache and vomiting were observed at the onset of treatment.

Within $72 \mathrm{~h}$ from the start of treatment, headache and vomiting were reported in a large number of patients. In a retrospective study of Suneja et al. headache was observed during radiation treatment in $50 \%$ of children with mainly medulloblastoma treated by proton beam therapy to the CSA [22]. Incidence peaked during the first 2 weeks of the treatment course [22]. The incidence of nausea and vomiting was 50 and $25 \%$, respectively [22]. In a group of 14 patients with medulloblastoma undergoing CSI by 3D conformal- and tomotherapy in combination with vincristine $(N=12 / 14)$, Huang et al. observed nausea/vomiting during the course of treatment in $64 \%$ of patients [21]. The combination of headache and vomiting at the onset of radiotherapy in patients treated with photons and protons, does suggest that cerebral edema resulting in increased intracranial pressure, was the main reason for these symptoms [25]. 


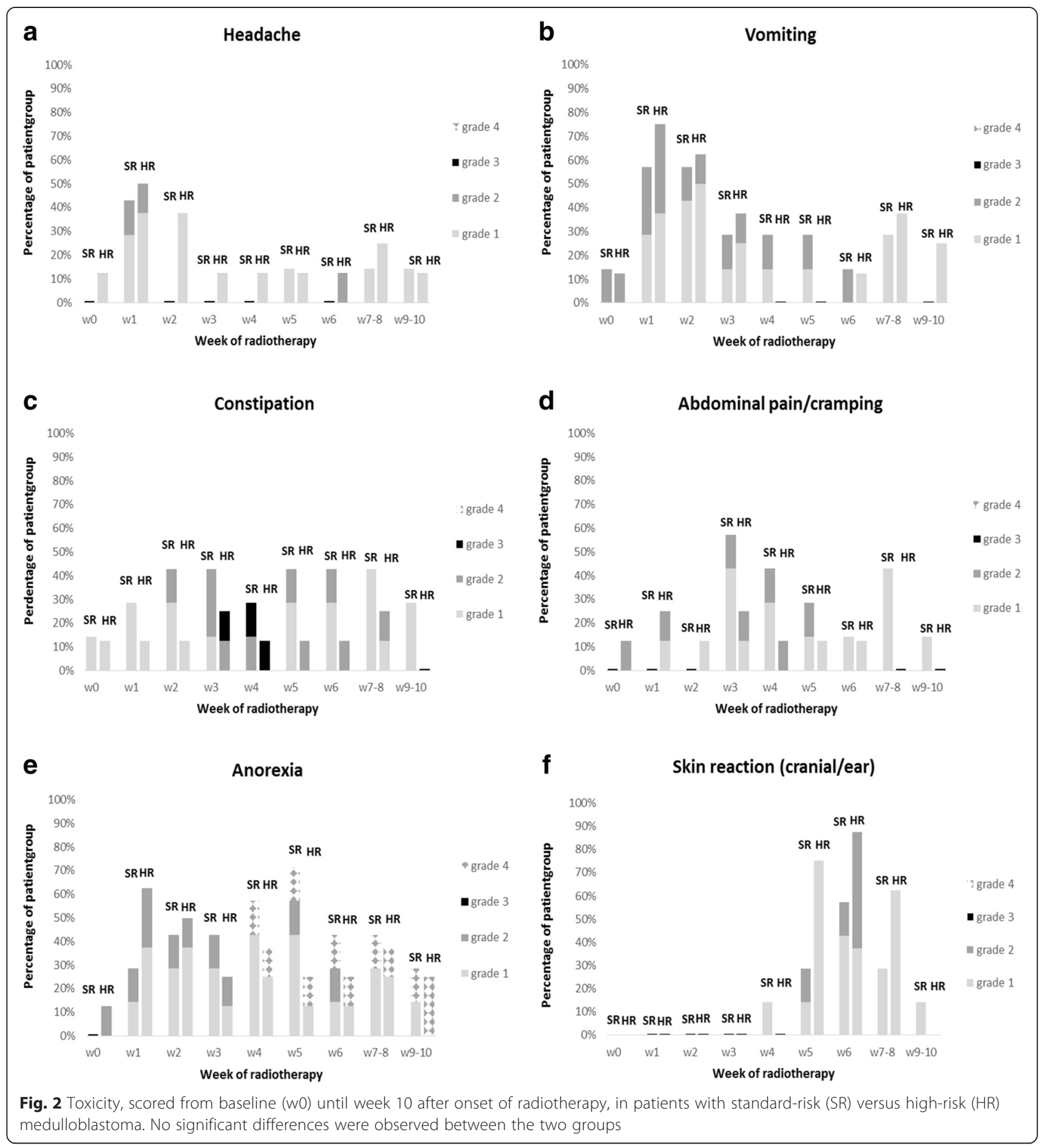

In order to reduce headache and vomiting, patients are given paracetamol, anti-emetics, dexamethasone or a combination of both [26]. Before start of radiation therapy, $13 \%$ of patients were dependent of steroids. During the first week of radiotherapy, $60 \%$ of the children needed dexamethasone to relieve symptoms. According to a double-blinded placebo-controlled randomized trial by Wong et al., the addition of dexamethasone to ondansetron as prophylaxis for radiation induced emesis from radiotherapy to the upper abdomen, resulted into a significant improvement of complete control of emesis during the first 2 weeks of fractionated radiotherapy [27].

Constipation and abdominal pain were only observed in patients receiving vincristine combined with radiotherapy and mostly from the third week of treatment. Anorexia was observed during the whole period of 


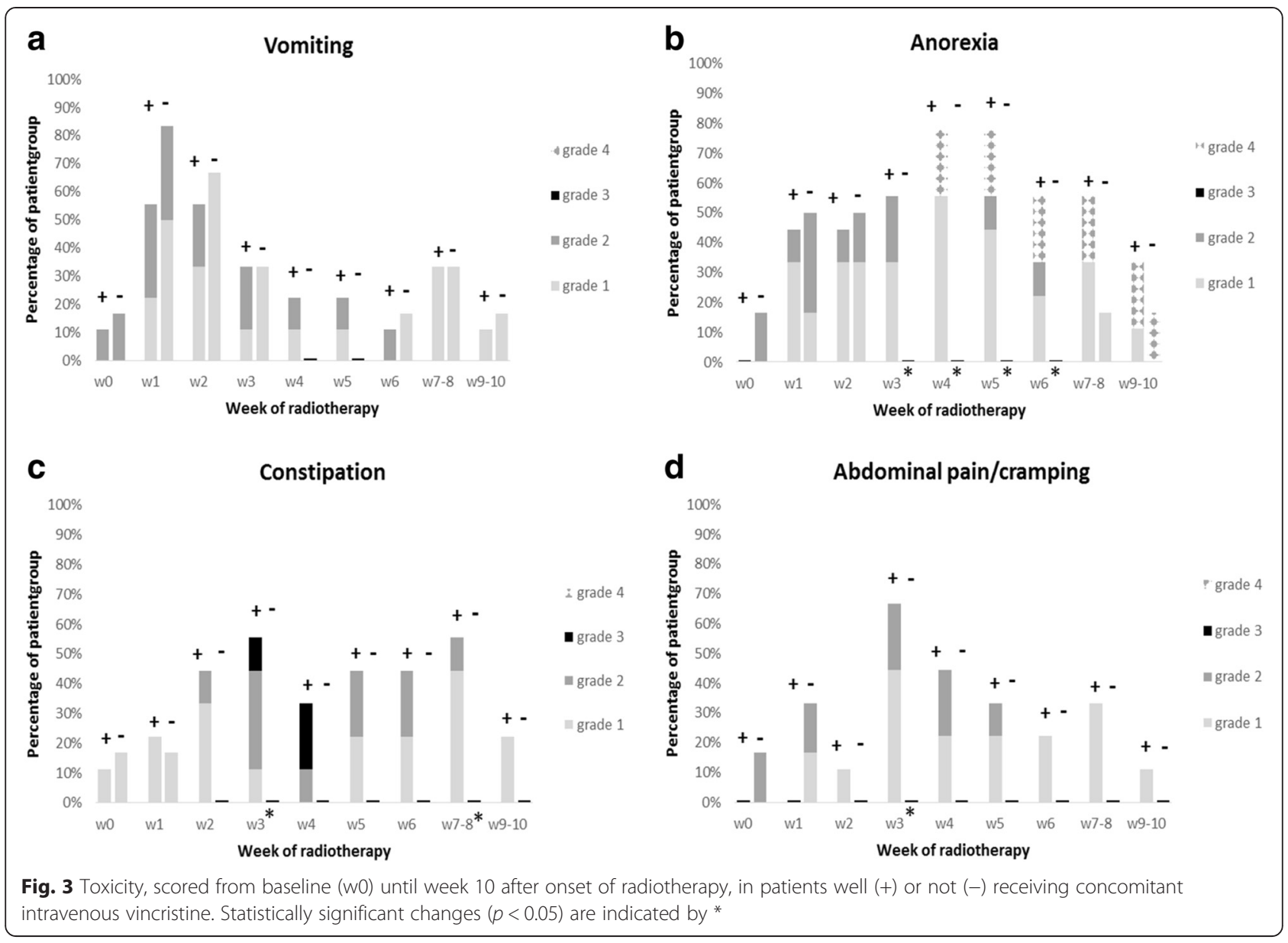

radiation treatment. However, from week 3 it was observed only in the group of patients receiving combined treatment. Suneja et al. demonstrated anorexia during the course of treatment in $83 \%$ of patients treated with proton beam therapy to the CSA [22]. Although significant higher radiotherapy doses were delivered to the CSA in patients with HR compared to SR medulloblastoma, there were no significant differences observed in anorexia, constipation and abdominal cramping. In contrast, almost $80 \%$ (versus $0 \%$ ) of patients receiving vincristine developed a combination of these symptoms. Acute gastro-intestinal toxicity during radiotherapy was mainly related to the concomitant use of vincristine and independent of the radiotherapy dose. Neurotoxicity of the gastro-intestinal tract, resulting in constipation and/ or abdominal pain, is a well-known side-effect of vincristine [28]. These symptoms are most prominent approximately 3 to 10 days after drug administration and usually resolve within several days after discontinuation of chemotherapy. The impaired motility of the intestines is dose related and most prominent if doses larger than $2.0 \mathrm{mg} / \mathrm{m}^{2}$ per bolus are used [28]. In the current analysis, vincristine related side-effects as constipation and abdominal pain were mainly observed from the third week of radiation treatment. Optimization of supportive care with laxatives can probably explain the decrease in abdominal pain/cramping from week 4. Neurotoxicity can be enhanced by the concomitant use of antiemetics, such as ondansetron and granisetron [29]. From the second week of radiotherapy, $54 \%$ of the children received one or a combination of these medications to relieve gastro-intestinal symptoms. Randomized controlled trials concerning prevention and/or management of chemotherapy-induced constipation in oncology patients are absent.

In line with Suneja et al. alopecia occurred in all patients from week 3 of treatment [22]. At week 6, $73 \%$ of patients developed faint erythema of the occipital area of the cranial skin. In some of them, erythema was combined with dry desquamation (40\%), or patchy desquamation confined to the skin folds of the auricle (33\%). A trend towards more skin toxicity was observed in patients with HR medulloblastoma. In contrast, radiation dermatitis of the skin overlying the spinal target volume was not observed. Kortmann et al. reported a comparable incidence of mild or marked erythema 
$( \pm 75 \%)$ in children with SR and HR medulloblastoma treated with a conventional CSI technique, without any significant difference between patients receiving neoadjuvant or concomitant chemotherapy [23]. According to Suneja et al., $100 \%$ of the patients receiving proton CSI developed grade 1 or 2 dermatitis (CTC, version 2.0) [22]. A benefit in radiation dermatitis in favor of photons compared to protons can be expected. An explanation for the lack of radiation dermatitis overlying the spinal skin observed in patients from the current analysis can be explained by the 5-beam arrangement with photons significantly reducing the dose close to the skin [18]. For the cranial part, with a target volume close to the skin, also a higher entrance dose is expected from proton beams compared to photon beams [14, 30]. Hair loss may be permanent with total doses greater than 40 Gy [31].

Overall treatment time is a prognostic factor for progression-free survival in patients with medulloblastoma [32, 33]. All our patients completed radiotherapy within 43 days. Due to poor compliance one patient resumed treatment after 1 day. Chang et al. reported interruptions of more than 3 days in $5 \%$ of children treated with electrons or photons [13]. In the multicenter HIT91 trial, Kortmann et al. observed interruptions of radiotherapy in $33 \%$ of patients receiving induction chemotherapy compared to $19 \%$ of patients in the maintenance chemotherapy arm [23]. This corresponded to a mean protraction of overall treatment time of 11.5 and 7.5 days, respectively. The main reasons for a different number of treatment interruptions observed in literature may be multifactorial: myelosuppression due to chemotherapy before radiotherapy, bone marrow sparing radiotherapy techniques, multicenter versus single center studies, the use of different hematological criteria for treatment interruption, and the quality of supportive care.

Although not an objective of this study, late toxicity remains a major issue after treatment for medulloblastoma. Secondary malignancy is one of the endpoints that needs attention when using highly-conformal photon techniques with larger areas of low-dose irradiation compared to the conventional techniques. Recently, the 10-year follow-up data on second malignancy after a combination of conventional radiotherapy and chemotherapy for 379 patients with non-disseminated medulloblastoma were published [34]. Interestingly, the majority of these second malignancies (at least 11 of 15) developed within the target volume of the craniospinal axis $(N=7)$, hematopoietic tissues $(N=3)$ or bone $(N=1)$ and will not be altered by treatment technique.

\section{Conclusion}

Headache and vomiting at onset, and gastro-intestinal toxicity during treatment were the major complaints in children with medulloblastoma undergoing CSI with IMRT. Subgroup analysis revealed the use of intravenous vincristine as main reason for gastro-intestinal toxicity. In an attempt to compare data from literature, the majority of items scored during radiotherapy seem to be independent of treatment technique used. Compared to protons, electrons and conventional techniques with photons, a benefit in favor of IMRT is observed for skin toxicity, especially for the spinal part.

\section{Abbreviations}

IMRT: Intensity-modulated radiation therapy; SR: Standard-risk; HR: High risk; CSI: Craniospinal irradiation; CSA: Craniospinal axis; CTV: Clinical target volume; PTV: Planning target volume; VMAT: Volumetric modulated arc therapy.

\section{Competing interests}

We declare that we have no competing interests.

\section{Authors' contributions}

GJ participated in the conception and design of the study. GJ was responsible for accrual, treatment and data collection. MC, GJ, JK participated in the analysis, interpretation of the data and writing of the report. CG, JS, EvL, reviewed the draft. All authors approved the final version of the report.

\section{Author details}

'Department of Radiation Oncology, Radboud University Medical Centre, Nijmegen, The Netherlands. ${ }^{2}$ Department of Pediatric Oncology, Radboud University Medical Centre, Nijmegen, The Netherlands. ${ }^{3}$ Department of Neurology, Radboud University Medical Centre, Nijmegen, The Netherlands. ${ }^{4}$ Department of Neurosurgery, Radboud University Medical Centre, Nijmegen, The Netherlands. ${ }^{5}$ Department of Radiation Oncology, University Medical Center Utrecht and Princess Maxima Center for Pediatric Oncology, Utrecht 3584 CX, The Netherlands.

Received: 11 August 2015 Accepted: 17 November 2015 Published online: 24 November 2015

\section{References}

1. Gajjar A, Chintagumpala M, Ashley D, Kellie S, Kun LE, Merchant TE, et al. Risk-adapted craniospinal radiotherapy followed by high-dose chemotherapy and stem-cell rescue in children with newly diagnosed medulloblastoma (St Jude Medulloblastoma-96): Long-term results from a prospective, multicentre trial. Lancet Oncol. 2006;7:813-20.

2. Packer RJ, Gajjar A, Vezina G, Rorke-Adams L, Burger PC, Robertson PL, et al. Phase III study of craniospinal radiation therapy followed by adjuvant chemotherapy for newly diagnosed average-risk medulloblastoma. J Clin Oncol. 2006;24:4202-8.

3. Pizer BL, Weston CL, Robinson KJ, Ellison DW, Ironside J, Saran F, et al. Analysis of patients with supratentorial primitive neuro-ectodermal tumours entered into the SIOP/UKCCSG PNET 3 study. Eur J Cancer. 2006;42:1120-8.

4. Calaminus $G$, Bamberg $M$, Jürgens $H$, Kortmann RD, Sörensen $N$, Wiestler $\mathrm{OD}$, et al. Impact of surgery, chemotherapy and irradiation on long term outcome of intracranial malignant non-germinomatous germ cell tumors: Results of the German Cooperative trial MAKEI 89. Klin Padiatr. 2004;216: 141-9.

5. Tekautz TM, Fuller CE, Blaney S, Fouladi M, Broniscer A, Merchant TE, et al. Atypical teratoid/rhabdoid tumors (ATRT): Improved survival in children 3 years of age and older with radiation therapy and high-dose alkylator-based chemotherapy. J Clin Oncol. 2005;1 (23):1491-9.

6. Merchant TE, Boop FA, Kun LE, Sanford RA. A retrospective study of surgery and reirradiation for recurrent ependymoma. Int J Radiat Oncol Biol Phys. 2008;1(71):87-97.

7. Ostrom QT, Gittleman H, Farah P, Ondracek A, Chen Y, Wolinsky Y, et al. CBTRUS statistical report: Primary brain and central nervous system tumors diagnosed in the United States in 2006-2010. Neuro Oncol. 2013;15:646-7.

8. Kaatsch P, Rickert CH, Kühl J, Schüz J, Michaelis J. Population-based epidemiologic data on brain tumors in German children. Cancer. 2001;92: 3155-64. 
9. Zeltzer PM, Boyett JM, Finlay JL, Albright AL, Rorke LB, Milstein JM, et al Metastasis stage, adjuvant treatment, and residual tumor are prognostic factors for medulloblastoma in children: Conclusions from the Children's Cancer Group 921 randomized phase III study. J Clin Oncol. 1999;17(3):832-45.

10. Children's Oncology Group COG-ACNS-0332 trial (NCT00392327): Efficacy of carboplatin administered concomitantly with radiation and isoretinoin as a pro-apoptotic agent in other than average risk medulloblastoma/PNET patients. A groupwide phase III study.

11. Tatcher M, Glicksman A. Field matching considerations in craniospinal irradiation. Int J Radiat Oncol Biol Phys. 1989;17:865-9.

12. Parker WA, Freeman CR. A simple technique for craniospinal radiotherapy in the supine position. Radiother Oncol. 2006;78:217-22.

13. Chang EL, Allen P, Wu C, Ater J, Kuttesch J, Maor MH. Acute toxicity and treatment interruption related to electron and photon craniospinal irradiation in pediatric patients treated at the University of Texas M.D. Anderson Cancer Center. Int J Rad Biol Phys. 2002;52:1008-16.

14. St Clair WH, Adams JA, Bues M, Fullerton BC, La Shell S, Kooy HM, et al. Advantage of protons compared to conventional X-ray or IMRT in the treatment of a pediatric patient with medulloblastoma. Int J Radiat Biol Phys. 2004:58:727-34.

15. Howell RM, Giebeler A, Koontz-Raisig W, Mahajan A, Etzel CJ, D'Amelio Jr AM, et al. Comparison of therapeutic dosimetric data from passively scattered proton and photon craniospinal irradiations for medulloblastoma. Radiat Oncol. 2012;7:116.

16. Parker W, Filion E, Roberge D, Freeman CR. Intensity-modulated radiotherapy for craniospinal irradiation: Target volume considerations, dose constraints, and competing risks. Int J Rad Biol Phys. 2007;69:251-7.

17. Pai Panandiker A, Ning H, Likhacheva A, Ullman K, Arora B, Ondos J, et al. Craniospinal irradiation with spinal IMRT to improve target homogeneity. Int J Radiat Oncol Biol Phys. 2007;68:1402-9.

18. Kusters JM, Louwe RJ, van Kollenburg PG, Kunze-Busch MC, Gidding CE, van Lindert EJ, et al. Optimal normal tissue sparing in craniospinal axis irradiation using IMRT with daily intrafractionally modulated junction. Int J Radiat Oncol Biol Phys. 2011;81:1405-14

19. Lopez Guerra JL, Marrone I, Jaen J, Bruna M, Sole C, Sanchez-Reyes A, et al. Outcome and toxicity using helical tomotherapy for craniospinal irradiation in pediatric medulloblastoma. Clin Transl Oncol. 2014;16:96-101.

20. Jefferies S, Rajan B, Ashley S, Traish D, Brada M. Haematological toxicity of cranio-spinal irradiation. Radiother Oncol. 1998;48:23-7.

21. Huang F, Parker W, Freeman CR. Feasibility and early outcomes of supineposition craniospinal irradiation. Pediatr Blood Cancer. 2010;54:322-5.

22. Suneja G, Poorvu PD, Hill-Kayser C, Lustig RA. Acute toxicity of proton beam radiation for pediatric central nervous system malignancies. Pediatr Blood Cancer. 2013;60:1431-6.

23. Kortmann RD, Kühl J, Timmermann B, Mittler U, Urban C, Budach V, et al. Postoperative neoadjuvant chemotherapy before radiotherapy as compared to immediate radiotherapy followed by maintenance chemotherapy in the treatment of medulloblastoma in childhood: Results of the German prospective randomized trial HIT'91. Int J Radiat Oncol Biol Phys. 2000;46: 269-79.

24. Packer RJ, Sutton LN, Elterman R, Lange B, Goldwein J, Nicholson HS, et al. Outcome for children with medulloblastoma treated with radiation and cisplatin, CCNU, and vincristine chemotherapy. J Neurosurg. 1994;81:690-8.

25. Sheline GE, Wara WM, Smith V. Therapeutic irradiation and brain injury. Int J Radiat Oncol Biol Phys. 1980;6:1215-28.

26. Roila F, Herrstedt J, Aapro M, Gralla RJ, Einhorn LH, Ballatori E, et al. Guideline update for MASCC and ESMO in the prevention of chemotherapy- and radiotherapy-induced nausea and vomiting: Results of the Perugia consensus conference. Ann Oncol. 2010;21 Suppl 5:232-43.

27. Wong RK, Paul N, Ding K, Whitehead M, Brundage M, Fyles A, et al. 5hydroxytryptamine-3 receptor antagonist with or without short-course dexamethasone in the prophylaxis of radiation induced emesis: A placebocontrolled randomized trial of the National Cancer Institute of Canada Clinical Trials Group (SC19). J Clin Oncol. 2006;24:3458-64.

28. Legha SS. Vincristine neurotoxicity: Pathophysiology and management. Med Toxicol. 1986;1:421-7.

29. Perez EA, Hesketh P, Sandbach J, Reeves J, Chawla S, Markman M, et al. Comparison of single-dose oral granisetron versus intravenous ondansetron in the prevention of nausea and vomiting induced by moderately emetogenic chemotherapy: A multicenter, double-blind, randomized parallel study. J Clin Oncol. 1998;16:754-60.
30. Levin WP, Kooy H, Loeffler JS, DeLaney TF. Proton beam therapy. Br J Cancer. 2005;93:849-54.

31. Lawenda BD, Gagne HM, Gierga DP, Niemierko A, Wong WM, Tarbell NJ, et al. Permanent alopecia after cranial irradiation: Dose-response relationship. Int J Radiat Oncol Biol Phys. 2004;60:879-87.

32. Taylor RE, Bailey CC, Robinson $\mathrm{K}$, Weston CL, Ellison D, Ironside J, et al. Results of a randomized study of preradiation chemotherapy versus radiotherapy alone for nonmetastatic medulloblastoma: The International Society of Paediatric Oncology/United Kingdom Children's Cancer Study Group PNET-3 Study. J Clin Oncol. 2003;21:1581-91.

33. Paulino AC, Wen BC, Mayr NA, Tannous R, Loew TW, Goldman FD, et al. Protracted radiotherapy treatment duration in medulloblastoma. Am J Clin Oncol. 2003:26:55-9.

34. Packer RJ, Zhou T, Holmes E, Vezina G, Gajjar A. Survival and secondary tumors in children with medulloblastoma receiving radiotherapy and adjuvant chemotherapy: Results of Children's Oncology Group trial A9961. Neuro Oncol. 2013:15:97-103.

\section{Submit your next manuscript to BioMed Central and we will help you at every step:}

- We accept pre-submission inquiries

- Our selector tool helps you to find the most relevant journal

- We provide round the clock customer support

- Convenient online submission

- Thorough peer review

- Inclusion in PubMed and all major indexing services

- Maximum visibility for your research 